\title{
Experimental Investigation on the Evolution of Hydrogen in Steel during the Electroslag Remelting Process
}

\author{
Wang Xiaohua ${ }^{a}$ (D, Li Ying ${ }^{b}$ \\ ${ }^{a}$ College of Chemistry, Chemical Engineering and Environmental Engineering, Liaoning Shihua University, \\ Fushun, Liaoning, 113001, China \\ ${ }^{b}$ Northeastern University, Shenyang, Liaoning, 110819, China
}

Received: November 21, 2018; Revised: February 18, 2019; Accepted: April 29, 2019

\begin{abstract}
Hydrogen, which is a harmful element, has a great effect on the mechanical properties of steel, should be removed during the steel manufacture process. The evolution of hydrogen content in steel during electroslag remelting process is experimentally investigated. The results show that during the electroslag remelting process, the hydrogen content in steel firstly increases steeply to maximum, then decreases to minimum and reaches the equilibrium. For a prefixed slag composition, the final hydrogen content in steel depends on the initial hydrogen content and the atmospheric moisture. When the electroslag remelting is operated under the argon protected atmosphere, the hydrogen in steel increased slightly. With the increase of the atmospheric moisture, the hydrogen content in steel increased significantly, and the larger atmospheric moisture is, the more significant influence on the hydrogen content in steel is. Moreover the mathematical formula to predict the hydrogen content in steel from the initial hydrogen content and the atmospheric moisture is derived: $w[\% \mathrm{H}]_{e}=0.359 w[\% \mathrm{H}]_{S}+0.016 \sqrt{p_{\mathrm{H}_{2} \mathrm{O}} / p^{\Theta}}+0.525$. It could be used to forecast the final hydrogen content in ESR ingot.
\end{abstract}

Keywords: Electroslag remelting, hydrogen content, slag/metal interface reaction, protective atmosphere.

\section{Introduction}

The Electroslag remelting process (ESR) has a great superiority in high quality ingot production with its excellent metallurgical reaction conditions and special melting crystallization method. To produce high quality large ESR ingots, the purity and chemical uniformity of electrode is a prerequisite. A number of studies have focus on this special smelting process ${ }^{1-4}$. Hydrogen and other element transfer during the electroslag remelting process were discussed in the previous works ${ }^{5,6}$. The ESR has a great advantage especially on controlling the hydrogen content of steel. The hydrogen content in steel has received much attention because of its importance to the quality of steel ${ }^{7,8}$. To understand hydrogen transport in the electroslag remelting process, a determination of the species in the gas, flux, and metal phases is necessary. It is believed ${ }^{9,10}$ that the hydrogen in the ESR ingots mainly comes from water vapors in the mold atmosphere, flux moisture content, slag system and hydrogen in the consumable electrode. The ESR process is generally conducted with highly active basic slags capable of absorbing substantial amounts of moisture. During the ESR process, the liquid metal forms at the consumable electrode and later the liquid metal detaches from the electrode tip and falls through the molten slag into the metal pool. It is supposed that the hydrogen in the liquid metal are removed by the slag/metal reaction in the slag pool during the formation and falling

*e-mail: yuechu1314@foxmail.com period of metal droplets, and the distribution equilibrium is established between the slag and metal as indicated by Kato ${ }^{11}$.

Moreover, many works were performed ${ }^{12-15}$ to investigate the hydrogen pick-up for several slags containing calcium fluoride and the slag with different states including new slag, pre-melted slag and recycling slag. In Mitchell's ${ }^{16}$ work, he briefly reviewed the slag components and properties evolving with the electroslag remelting process, and the effects of slag on the hydrogen transfer and inclusion composition control. He considered that the transport behavior of the slags was treated with relation to the electrochemical, heat and mass transfer processes. N. M. Chuiko ${ }^{17}$ found that the primary source of hydrogen content increase of ESR ingots is the hydrogen in the electrodes, flux moisture, and water vapor in the mold atmosphere. A reduction in the hydrogen content of ESR metal can be achieved mainly by degasification of the original steel, careful calcining of the fluxes and reducing the partial pressure of water vapors in the mold atmosphere during melting.

Several investigators ${ }^{18,19}$ had studied on the behavior of hydrogen during electroslag remelting process and obtained the results for the individual operating conditions, but the theoretically fundamental knowledge of hydrogen transfer during ESR is still needed. In this paper, the hydrogen transfer from the atmosphere through the slag pool into the molten metal pool finally was investigated. The experiments focus on the influence of the atmosphere moisture and metal/ slag reaction to the hydrogen transfer and aim to find out the relationship between initial hydrogen content and final hydrogen content in different atmosphere moisture. 


\section{Experiment Description}

In order to study the hydrogen transfer during electroslag remelting process, the special steel L80-13Cr, whose composition is listed in Table 1, was remelted under air atmosphere and protective atmosphere by using a laboratory $\mathrm{MoSiO}_{2}$ furnace. The present work was designed to study the hydrogen transfer process from the ambient atmosphere around furnace to the steel during ESR process. At the same time, the effect of different atmospheric moisture on the hydrogen transfer and hydrogen content was discussed. The aim is to find out the main road of hydrogen transfer and get a formula to illustrate the relationship between the water moisture and hydrogen content in steel.

\subsection{Sample preparation and experiment apparatuses}

Before the experiment, the steel samples should be manufactured to round bars of $45 \mathrm{~mm}$ in diameter, and 50 $\mathrm{mm}$ in length, which were thereafter used as consumable electrode in experiments. The steel samples were polished by sand paper to remove iron oxide on the surface, and the steel samples were soaked in the $\mathrm{HCl}$ solution for several hours, and washed by deionizes water. Then the steel samples were polished by sand paper again and again until the surface of the samples was bright and had no dark pot.

$\mathrm{AMoSi}_{2}$ furnace, which consists of purification system, heating system, and control system, was used to simulate the ESR process. To eliminate the effect of slag charge on the experimental results, the slag used for the experiment in this study is $\mathrm{CaF}_{2}-\mathrm{Al}_{2} \mathrm{O}_{3}-\mathrm{CaO}-\mathrm{SiO}_{2}$ quaternary slag system and its mass fraction distribution ratio is unchanged. The composition of slag used in the experiments is listed in Table 2.

In order to remove the moisture in slag, the slag need baking before used. $\mathrm{CaF}_{2}, \mathrm{Al}_{2} \mathrm{O}_{3}, \mathrm{CaO}, \mathrm{SiO}_{2}$ are respectively prepared with the crucible in the muffle furnace, at $850^{\circ} \mathrm{C}$ under constant temperature for 10 hours. According to the stoichiometric ratio request, the corresponding raw material are mixed and formed into tablet for later use.

In the experiments, $99.99 \%$ argon is adopted as the protective atmosphere. Before the argon arrived and entered into the furnace, it was dehydrated with color-variable silica gel and phosphorus pent oxide $\left(\mathrm{P}_{2} \mathrm{O}_{5}\right)$.
At last, the pretreated steel samples were remelted in $\mathrm{CaF}_{2}-\mathrm{Al}_{2} \mathrm{O}_{3}-\mathrm{CaO}-\mathrm{SiO}_{2}$ quaternary slag under different atmosphere.

\subsection{Experimental procedure}

Prepared steel sample was stored in a $\mathrm{MgO}$ crucible and put into the $\mathrm{MoSi}_{2}$ furnace, and then the furnace was starting to heat up. When the temperature is close to the aim temperature, the prepared slag was added into the crucible in the furnace. Well mixed was needed to make the slag and the molten metal reacted deeply. The outlet temperature of the furnace cooling water was maintained less than $298 \mathrm{~K}\left(25^{\circ} \mathrm{C}\right)$. The first group samples were remelting under atmosphere, without argon as protection gas, and the second group samples were remelting under argon atmosphere (argon flow rate of $2 \mathrm{~L} / \mathrm{min}$ ) with different initial hydrogen content, at the last third group samples were remelting under different moisture (argon flow rate of $2 \mathrm{~L} / \mathrm{min}$, the argon saturated with water vapor at $10^{\circ} \mathrm{C}$, $20^{\circ} \mathrm{C}, 30^{\circ} \mathrm{C}$ ).

During the remelting, samples were sucked up into quartz tubes from the metal pools with a rubber bulb. All samples were stored in a desiccator before analysis. Hydrogen in steel was analyzed quantitatively by the TCH600.

\section{Experimental Results and Discussion}

\subsection{Effect of different ambient atmosphere around furnace on hydrogen content}

In order to understand the role played by the atmosphere around the furnace in the ESR process, a lot of experiments had been carried out for studying the influence of different atmosphere over the slag pool on the hydrogen content in steel when the initial hydrogen content was very low.

As shown in Figure 1, it is to be noted that when the atmosphere around the furnace is different, the hydrogen content in the samples is quite different in different time. When the ingot was remelted in the atmosphere, the change of the hydrogen content in the samples is shown in Figure 1(a). It can be noted that the hydrogen content ascends up very quickly during the atmosphere remelting.

Table 1. Chemical composition of materials remelted (wt, \%).

\begin{tabular}{ccccccccc}
\hline Element & $\mathrm{C}$ & $\mathrm{Mn}$ & $\mathrm{O}$ & $\mathrm{H}$ & $\mathrm{S}$ & $\mathrm{Cr}$ & $\mathrm{P}$ & $\mathrm{Si}$ \\
\hline Composition & $0.18 \sim 0.21$ & $0.45 \sim 0.65$ & $\leq 0.004$ & $\leq 0.0002$ & $\leq 0.008$ & $12.5 \sim 14$ & $\leq 0.02$ & $0.35 \sim 0.55$ \\
\hline
\end{tabular}

Table 2. Ratio of the elements in slag (\%).

\begin{tabular}{ccccc}
\hline Composition & $\mathrm{CaF}_{2}$ & $\mathrm{Al}_{2} \mathrm{O}_{3}$ & $\mathrm{CaO}$ & $\mathrm{SiO}_{2}$ \\
\hline Ratio & 59 & 18 & 15 & 8 \\
Purity & $\leq 95$ & $\leq 97$ & $\leq 98$ & $\leq 97$ \\
\hline
\end{tabular}


In the next experiments, the argon was used to be the protective gas and the speed is $2 \mathrm{~L} / \mathrm{min}$. The hydrogen content increased so fast to a maximum of $4 \mathrm{ppm}$, and then got down sharply with the time. When the time approached to $4 \mathrm{~h}$, the hydrogen content in ingot was reduced to $2 \mathrm{ppm}$ and keeps invariant. This observation has led to the proposal that when the argon was used to be the protective gas it can prevent the hydrogen content raise further during the remelting process. It is also proved by other researchers ${ }^{20}$.

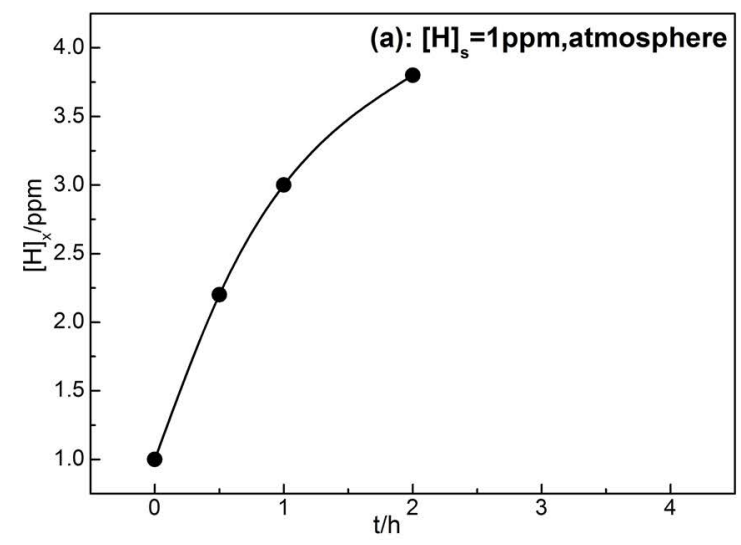

\subsection{Effect of different initial hydrogen content on hydrogen level}

The following experiment was designed to study the effect of different initial hydrogen content on hydrogen level in steel. In these experiments four sample having different initial hydrogen content was used to study the hydrogen content in steel. The influence of the initiative hydrogen content on hydrogen content in steel during ESR under argon is shown in Figure 2.

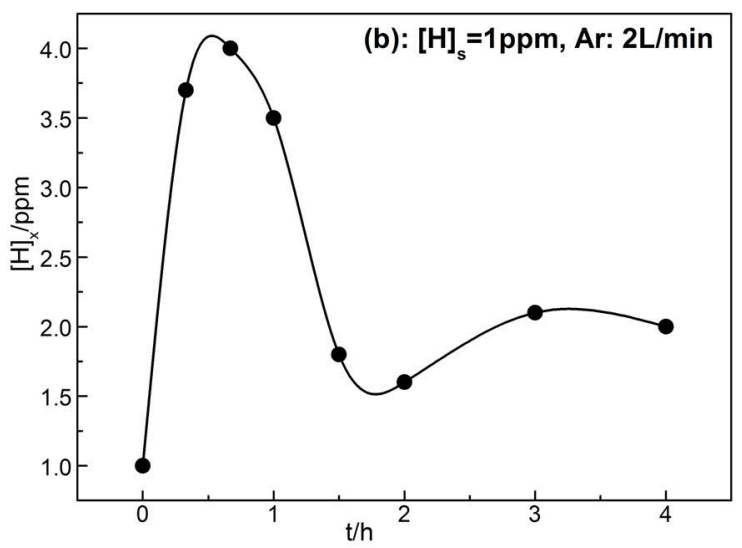

Figure1. Influence of atmosphere on hydrogen content in steel during ESR
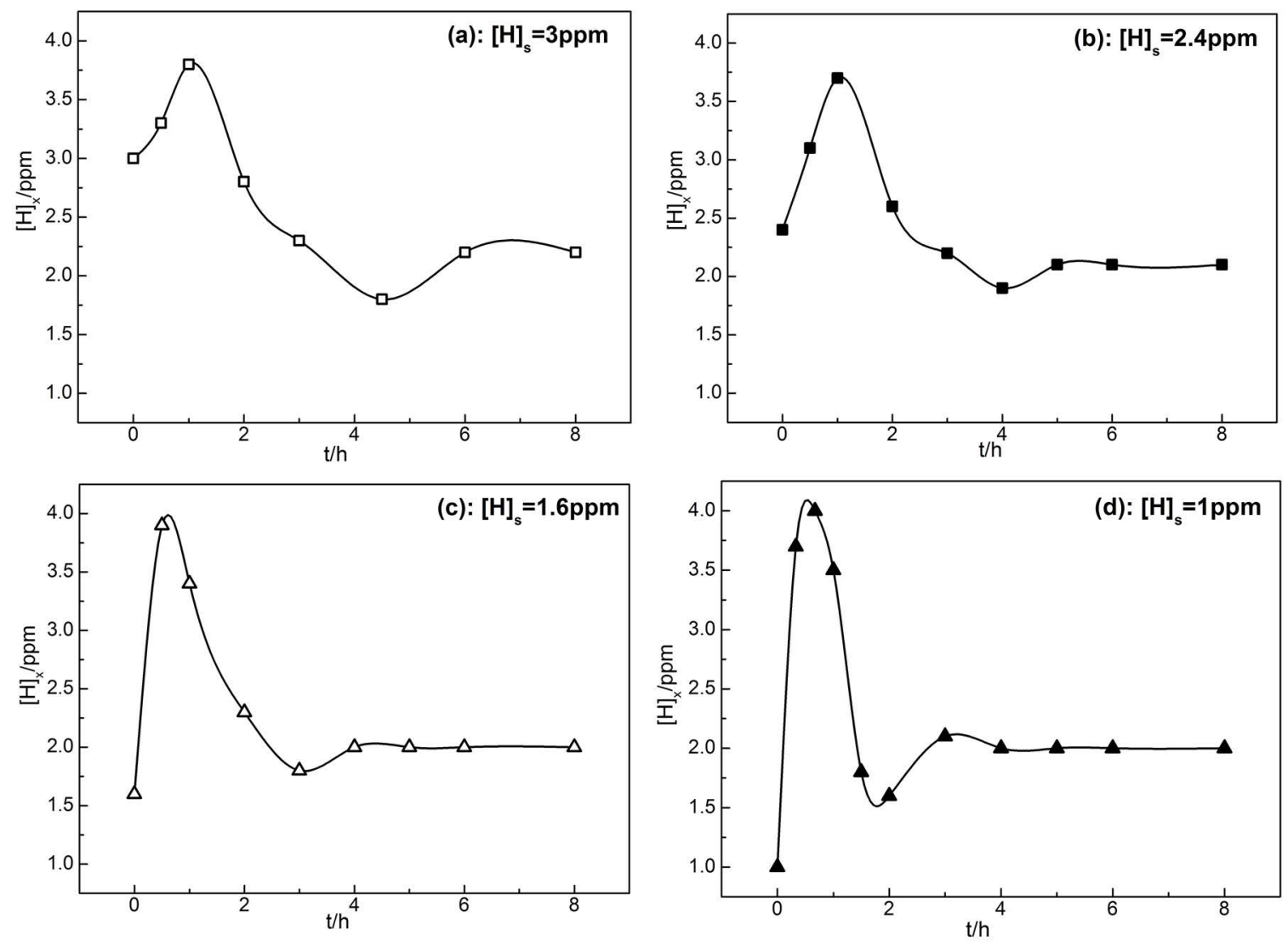

Figure 2. Influence of initial hydrogen content on hydrogen content in steel during ESR 
This diagram demonstrates that when the initial hydrogen content in electrode was different, the hydrogen content in steel changed differently either. They all had a similar tendency that at first they increased rapidly, after reach the maximum, they began to decline, then reached to their minimum, and finally the hydrogen content maintained at about 2 ppm. From the Figure 2(a) it also can be confirmed that the time of the hydrogen content variation to $2 \mathrm{ppm}$ is $8 \mathrm{~h}$ when the initial hydrogen content is $3 \mathrm{ppm}$. In Figure 2(b) and Figure 2(c) the time is about $6 \mathrm{~h}$ and less than $6 \mathrm{~h}$ when the initial hydrogen content is $2.5 \mathrm{ppm}$ and $1.6 \mathrm{ppm}$ respectively, but in Figure 2(d) the time is the shortest, less than $3 \mathrm{~h}$, when the initial hydrogen content is $1 \mathrm{ppm}$. It can be concluded that when the higher initial hydrogen content in ingot, the longer time are needed to achieve the final hydrogen content of $2 \mathrm{ppm}$. This phenomenon is explained when the slag system was determined, the hydrogen adsorption and hydrogen permeation was fixed, so that no matter the initial hydrogen content is high or low, the hydrogen absorbed by the slag was constant. In this case when the experiment began, the hydrogen in the whole system, not only the hydrogen in steel and in slag but also the atmospheric moisture, needs the total equilibrium. That is to say the higher initial hydrogen content in steel, the less time reaction needs to reach the balance, and the higher final hydrogen content in steel.

\subsection{Effect of different atmospheric moisture around furnace on hydrogen}

In order to understand the role played by the atmospheric moisture around the furnace in the ESR process, a lot of experiments had been carried out for studying the influence of different atmospheric moisture on the hydrogen content in steel.

Figure 3 compares the hydrogen content in steel during ESR with the different atmospheric moistures. The higher temperature of the argon atmosphere, the larger moisture in the argon is. When the argon saturated with water vapor at $10^{\circ} \mathrm{C}$, the variation of hydrogen content in ingot is not obvious during the constant temperature process, and the original hydrogen content in steel is $2.4 \mathrm{ppm}$, after $2 \mathrm{~h}$ the hydrogen content increases to $2.7 \mathrm{ppm}$. With the extending of time the hydrogen content in steel increases, but the increasing speed is relatively slow. When the moisture in argon increased gradually, the transfer rate of hydrogen from the atmosphere to steel increases obviously, thus the hydrogen content in steel increases significantly too. When the argon saturated with water vapor at $30^{\circ} \mathrm{C}$, the water in the atmosphere diffuses into steel rapidly, $2 \mathrm{~h}$ later the hydrogen content in the steel reaches the maximum. The hydrogen content in steel sample has no obvious change with the increase of time, that is to say the hydrogen content in the steel sample reached saturation. It is evident that when the atmospheric moisture is larger, the influence of atmospheric moisture on the hydrogen content in steel is more significant. This phenomena was also proved by Dong ${ }^{21}$ in different experimental conditions.

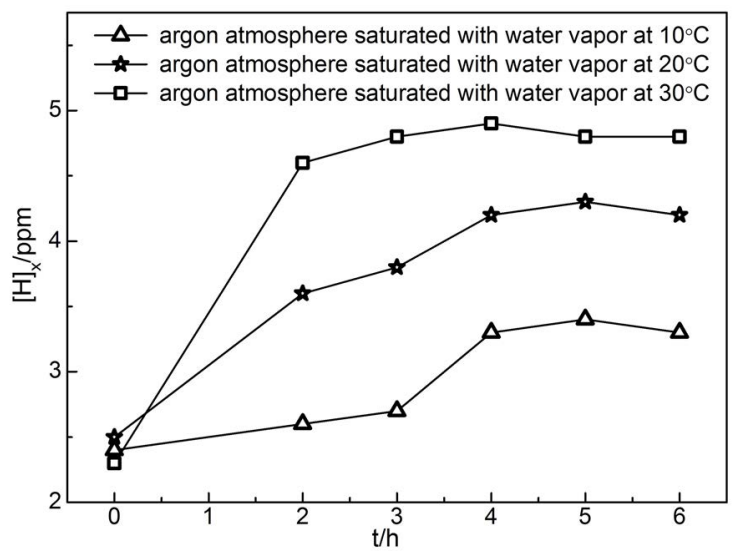

Figure 3. Influence of atmospheric moisture on the hydrogen content in steel during ESR

As mentioned above, when the slag system was fixed, the hydrogen adsorption and hydrogen permeation was fixed, so that no matter the initial hydrogen content is high or low, the hydrogen absorbed by the slag was constant. The reason for this phenomenon is that when the atmospheric moisture is larger, the hydrogen concentration in the gas/slag interface was higher and it is benefit for the reaction at the interface, so that the hydrogen concentration was higher too. At the same time, the time used to reach their maximum and minimum value was shorter, and the time reached the equilibrium was shorter either. It leads to the different hydrogen content in the samples at different times under atmospheric moisture.

\section{Hydrogen Transfer}

It is mostly believed ${ }^{15-17}$ that the gas/slag reaction (1) and a slag/metal reaction (2) are the important reaction for hydrogen transfer during the electroslag remelting process as follow.

Gas/slag reaction:

$$
\mathrm{H}_{2} \mathrm{O}+\left(0^{2-}\right)=2\left(\mathrm{OH}^{-}\right)
$$

Slag/metal reaction:

$$
2\left(\mathrm{OH}^{-}\right)+\left(\mathrm{M}^{2+}\right)=[\mathrm{M}]+2[\mathrm{H}]+2[\mathrm{O}]
$$

Therefore, we try to discuss them respectively.

First of all, we assumed that slag above atmosphere is steady state and the hydrogen in the liquid steel is uniformly distributed, i.e. ignoring the diffusion of hydrogen in the atmosphere to the gas/slag interface and the slag-metal interface to the molten steel.

Based on the above assumption, the gas phase $P_{\mathrm{H}_{2} \mathrm{O}}$ is equal to the vapor pressure in the gas/slag interface. Assume that fluid components inside the molten slag component $\left(\mathrm{OH}^{-}\right)$concentration is $C^{\infty}{ }_{\left(\mathrm{OH}^{-}\right)}$, the concentration $C^{i}{ }_{\left(\mathrm{OH}^{-}\right)}$for the phase interface, and $\mathrm{C}_{\left(\mathrm{OH}^{-}\right)}^{i}>C^{\infty}{ }_{\left(\mathrm{OH}^{-}\right)} . \mathrm{H}_{2} \mathrm{O}$ is transferred or permeated from gas into slag fluid infinitesimal with the form $\left(\mathrm{OH}^{-}\right)$. After a time $t_{\mathrm{e}}$, the hydroxyl ion concentration of 
$\left(\mathrm{OH}^{-}\right)$in the fluid microelement increase $\triangle C$, and leaves the interface migration into the slag inside, the position vacated is later occupied by the new fluid microelement. Thus, the surface is constantly updated with the species transfer.

The first step of hydrogen move into metal is hydrogen transfer on the interface between the gas and the slag pool. Based on Fick's second law,

$$
\frac{\partial C_{\left(\mathrm{OH}^{-}\right)}}{\partial t}=D_{\left(\mathrm{OH}^{-}\right)} \frac{\partial^{2} C_{\left(\mathrm{OH}^{-}\right)}}{\partial x^{2}}
$$

The boundary conditions are given as followings,

$$
\begin{aligned}
& t=0, x \geq 0, C_{\left(\mathrm{OH}^{-}\right)}=C_{\left(\mathrm{OH}^{-}\right)}^{\infty} ; t_{e} \geq t>0, x=0, C_{\left(\mathrm{OH}^{-}\right)}= \\
& C_{\left(\mathrm{OH}^{\prime}\right)}^{i} ; x=\infty, C_{\left(\mathrm{OH}^{-}\right)}=C_{\left(\mathrm{OH}^{-}\right)}^{\infty} .
\end{aligned}
$$

On the solutions of equation (3),

$$
C_{\left(\mathrm{OH}^{-}\right)}=C_{\left(\mathrm{OH}^{-}\right)}^{i}-\left(C_{\left(\mathrm{OH}^{-}\right)}^{i}-C_{\left(\mathrm{OH}^{-}\right)}^{\infty}\right) \operatorname{erf}\left(\frac{x}{2 \sqrt{D t}}\right)
$$

The "erf" in the equation (4) is the error function symbols.

In the interface where $x=0$, the diffusion flux of $\left(\mathrm{OH}^{-}\right)$ components is given by

$$
\begin{gathered}
J_{\left(\mathrm{OH}^{\top}\right)}^{i}=-D\left(\frac{\partial C_{\left(\mathrm{OH}^{-}\right)}}{d x}\right)_{x=0}= \\
\sqrt{\frac{D}{\pi t_{e}}}\left(C_{\left(\mathrm{OH}^{\top}\right)}^{i}-C_{\left(\mathrm{OH}^{\top}\right)}^{\infty}\right)
\end{gathered}
$$

Assuming that the reaction (1) at gas/slag interface is very fast, it's close to equilibrium, so that we can obtain that

$$
w\left(\% \mathrm{OH}^{-}\right)_{i}=\sqrt{K_{1} \cdot\left(p_{H_{2} O} / p^{\Theta}\right) \cdot a_{0^{2}}}
$$

From Eq. (5) to Eq. (6), we can get

$$
\begin{gathered}
-\frac{d w\left(\% \mathrm{OH}^{-}\right)}{d t}=\frac{A}{V_{m}} \sqrt{\frac{D}{\pi t_{e}}} \\
\left(\sqrt{K_{1} \cdot\left(p_{\mathrm{H}_{2} \mathrm{O}} / p^{\Theta}\right) \cdot a_{0^{2}}-w\left(\% \mathrm{OH}^{-}\right)_{\infty}}\right)
\end{gathered}
$$

where $V_{\mathrm{m}}$ is the volume of the liquid metal, $\mathrm{m}^{3}, A$ is the area of slag/metal boundary, $\mathrm{m}^{2}, D$ is the diffusion coefficient of hydrogen, $\mathrm{m}^{2} / \mathrm{s}, t_{\mathrm{e}}$ is the equilibrium time, $\mathrm{s}, K_{1}$ is the equilibrium constant for the reaction Eq. (1) at the gas/ slag interface, $a_{\mathrm{O}}^{2-}$ is the basicity of slag, and $p_{\mathrm{H}_{2} \mathrm{O}}$ is the partial pressure of moisture in the atmosphere above the slag pool, Pa.

After the hydrogen in the atmosphere penetrates into the slag pool, its diffusion depends on the concentration difference. It is assumed that the slag has completely dried, i.e. the influence of the water contained in the slag was

$$
J_{r}=\frac{1}{17} K_{r}\left(C_{\left(\mathrm{OH}^{-}\right)}-C_{(\mathrm{OH})^{\prime}}\right)
$$

At the step of hydrogen transfer on the interface between the slag pool and metal pool, the concentration of hydrogen in the slag pool is $C_{\left(\mathrm{OH}^{-}\right)}$, when it spreads to the slag/metal interface, its concentrations decreased to $C^{*}{ }_{(\mathrm{OH})}$, and transforms into a product by interfacial reaction, the product's concentration is $C^{*}{ }_{(\mathrm{H})}$. At last, the product apart from internal diffusion from the interface into the liquid steel, its concentration reduced to $C_{[\mathrm{H}]}$.

The whole process is composed of three steps in series, the rate of the diffusion flux in molten slag pool is $J_{1}=$ $\left(\mathrm{C}_{(\mathrm{OH})^{-}} C^{*}{ }_{(\mathrm{OH})^{\prime}}\right)$, the interfacial chemical reaction rate is $J_{2}=k_{2}\left(C^{*}{ }_{(\mathrm{OH})}{ }^{-} C_{(\mathrm{OH})}^{\mathrm{e}}\right)$, the rate of the diffusion flux in metal pool is $J_{3}=k_{3}\left(C^{*}{ }_{[\mathrm{H}]}-C_{[\mathrm{H}]}\right)$, where $k_{1}$ is the mass transfer coefficient of $\left(\mathrm{OH}^{-}\right), \mathrm{m} / \mathrm{s}, k_{2}$ is the rate coefficient of the interfacial chemical reaction, $k_{3}$ is the mass transfer coefficient of $[\mathrm{H}]$, $\mathrm{m} / \mathrm{s}$, and $\mathrm{C}_{(\mathrm{OH})}^{e}$ is the equilibrium concentration.

Here the interfacial chemical reaction can be approximate considered that

$$
2\left(\mathrm{OH}^{-}\right)+\left(\mathrm{Fe}^{2+}\right)=2[\mathrm{O}]+2[\mathrm{H}]+[\mathrm{Fe}]
$$

The reaction speed of reaction (8) under high temperature metallurgical process is fast, it can be considered in equilibrium state, and the interfacial concentrations are close to the equilibrium concentration. When the slag system and reaction conditions are determined, the distribution ratio of $[\mathrm{H}]$ and $\left(\mathrm{OH}^{-}\right)$in the slag and liquid steel $L_{[\mathrm{H}]}$ is a determinate value, it can get

$$
L_{H}=\frac{C_{\left(\mathrm{OH}^{-}\right)}^{e}}{C_{[H]}^{e}}=\frac{C_{\left(\mathrm{OH}^{-}\right)}^{*}}{C_{[H]}^{*}}
$$

Based on the double-film theory, the mass transfer on both side of the interface is in a steady-state, and the whole process also in steady-state, so that $J_{1}=J_{2}=J_{3}=J$.

Due to the interface concentration cannot be directly measured by experiment, $C^{*}{ }_{(\mathrm{OH})}$ and $C^{*}{ }_{[\mathrm{H}]}$ should be eliminated.

$$
J=\frac{C_{\left(\mathrm{OH}^{-}\right)}-L_{[H]} C_{[H]}}{\frac{1}{k_{1}+\frac{1 L_{H}}{k_{2}+k_{3}}}}
$$

Because the chemical reactions during the high temperature metallurgical process is very fast, it does not become a restrictive step, therefore, resistance of chemical reactions $1 / k_{2}$ can be ignored. In this case, the rate is mainly controlled by diffusion mass transfer in two-phase control, that is,

$$
\begin{gathered}
-\frac{d w\left(\% \mathrm{OH}^{-}\right)}{d t}=\frac{d w[\% \mathrm{H}]}{d t}= \\
\frac{A}{V_{m}} \frac{w\left(\% \mathrm{OH}^{-}\right)-L_{[H]} w[\% \mathrm{H}]}{\frac{1}{k_{1}+\frac{\left(17 \rho m L_{H}\right)}{\left(\rho_{s} k_{3}\right)}}}
\end{gathered}
$$

where $\rho_{\mathrm{s}}$ is the density of the molten slag, $\mathrm{g} / \mathrm{cm}^{3}, \rho_{\mathrm{m}}$ is the density of the molten metal, $\mathrm{g} / \mathrm{cm}^{3}, L_{\mathrm{H}}$ is the distribution coefficient of $[\mathrm{H}]$ in the slag/liquid metal. If hydrogen diffusion from gas to slag and in the slag pool are not restricted in the diffusion process, the hydrogen diffusion from gas to slag and in the slag pool reaches the steady state, Eq. (7) and Eq. (12) are equal, the $w\left(\% \mathrm{OH}^{-}\right)$is eliminated. During the experiment, the slag system and steel has been fixed, the mass transfer coefficient of hydrogen in the molten slag and in molten steel are considered as constant, 
the oxidability and density of the slag, the density of the molten steel, and the distribution ratio of hydrogen in slag/ metal are also considered as constant. The crucible and ingot are ensured to be the same condition in every experiment so that the volume of the molten steel and the area of the interface between molten slag and molten metal can be regarded as a constant value. Thus,

$$
\begin{aligned}
& \frac{d w[\% \mathrm{H}]}{d t}=\alpha \sqrt{p_{H_{2} O} / p^{\Theta}}+\beta w[\% \mathrm{H}] \\
& \alpha=\frac{V_{m}}{A} \frac{\sqrt{K_{1}} \cdot a_{O^{2-}}}{\frac{1}{k_{1}}+\frac{17 \cdot \rho_{m} \cdot L_{H}}{k_{3} \cdot \rho_{s}}+\sqrt{\frac{\pi t_{e}}{D}}}, \\
& \beta=-\frac{V_{m}}{A} \frac{L_{H}}{\frac{1}{k_{1}}+\frac{17 \cdot \rho m \cdot L_{H}}{K_{3} \cdot \rho_{S}}+\sqrt{\frac{\pi t_{e}}{D}}}
\end{aligned}
$$

where $V_{\mathrm{m}}$ is the volume of the molten metal, $\mathrm{m}^{3} ; A$ is the area of the slag/metal interface, $\mathrm{m}^{2} ; D$ is the diffusion coefficient of hydrogen, $\mathrm{m}^{2} / \mathrm{s} ; t_{\mathrm{e}}$ is the equilibrium time, $\mathrm{s} ; L_{\mathrm{H}}$ is the distribution coefficient of hydrogen in slag/metal; $\rho_{\mathrm{m}}$ is the density of the molten metal; $\mathrm{g} / \mathrm{cm}^{3} ; K_{1}$ is the equilibrium constant of the gas/slag interfacial reaction; $\rho_{\mathrm{s}}$ is the density of the molten slag, $\mathrm{g} / \mathrm{cm}^{3} ; k_{1}$ is the mass transfer coefficient of $\mathrm{OH}^{-}$in slag, $\mathrm{m} / \mathrm{s} ; a_{\mathrm{O}}{ }^{2-}$ is the basicity of slag; $k_{3}$ is the mass transfer coefficient of $\mathrm{H}$ in molten metal, $\mathrm{m} / \mathrm{s} ; p_{\mathrm{H}_{2} \mathrm{O}}$ is the partial pressure of water moisture in atmosphere, $\mathrm{Pa}$.

Integral solution of the Eq. (13) can be given as follow

$$
w[\% \mathrm{H}]=C e^{\beta t}-C^{\prime} \frac{\sqrt[\alpha]{p_{H_{2} O} / p^{\Theta}}}{\beta+C^{\prime \prime}}
$$

where $\alpha, \beta, C, C^{\prime}, C^{\prime \prime}$ are the integral constant.

By the integral equation, it's known that when the ESR process at the beginning and end,

$$
\begin{gathered}
w[\% \mathrm{H}]_{s}=w[\% \mathrm{H}] \mid t=0=C-C^{\prime} \frac{\sqrt[\alpha]{p_{\mathrm{H}_{2} \mathrm{O}} / p^{\Theta}}}{\beta+C^{\prime \prime}} \\
w[\% \mathrm{H}]_{e}=w[\% \mathrm{H}] \mid t=\infty=-C^{\prime} \frac{\sqrt[\alpha]{p_{\mathrm{H}_{2} \mathrm{O}} / p^{\Theta}}}{\beta+C^{\prime \prime}}
\end{gathered}
$$

$$
\text { That is } w[\% \mathrm{H}]_{e}=A_{0} w[\% \mathrm{H}]_{s}+A_{1} \sqrt{p_{H_{2} O} / p^{\Theta}}+A_{2}
$$

where $w[\% \mathrm{H}]_{\mathrm{e}}$ is the final hydrogen content in the ingot, ppm; $p_{\mathrm{H}_{2} \mathrm{O}}$ is the partial pressure of moisture in atmosphere, $\mathrm{Pa} ; A_{0}, A_{1}, A_{2}$ are the constants depends on the slag, steel and other conditions; $w[\% \mathrm{H}]_{\mathrm{s}}$ is the initial hydrogen content in the electrode, ppm.

By the hydrogen diffusion dynamics model during ESR process shows that when the moisture pressure in the atmosphere increases, the diffusion rate of hydrogen increases, the water in the atmosphere diffuses to the slag/ gas interface to take the reaction $\mathrm{H}_{2} \mathrm{O}(\mathrm{g})+\left(\mathrm{O}^{2-}\right)=2\left(\mathrm{OH}^{-}\right)$, and the $\left(\mathrm{OH}^{-}\right)$diffuse to the surface of the slag so that the concentration of $\left(\mathrm{OH}^{-}\right)$increases in a unit time, making the concentration of $\left(\mathrm{OH}^{-}\right)$on the slag/gas interface higher than that of slag/metal interface, therefore the diffusion rate of $\left(\mathrm{OH}^{-}\right)$from the slag/gas interface to the slag/metal interface increases. It makes the $\left(\mathrm{OH}^{-}\right)$concentration on the slag/metal interface increase, also prompted the interface reaction between slag/metal in the positive direction, enables the concentration of $[\mathrm{H}]$ in the liquid steel increasing, namely the higher hydrogen content in liquid steel.

The experimental data proved that when the other conditions remain unchanged, the hydrogen content in steel increases with the increasing of humidity in the protective gas.

Combined with the experiment data under different argon protection, we get 6 equations from the dynamic model of Eq. (18). Combination of two of the equations, 15 groups of $\alpha$ and $\beta$ values can be calculated. By substitution of these values, 15 formulas of the dynamic model can be expressed. The diffusion dynamics model in the process of electroslag remelting under the experimental condition of hydrogen is given as follows

$$
\frac{d w[\% \mathrm{H}]}{d t}=9.9 \times 10^{-6} \sqrt{p_{H_{2}} / p^{\Theta}}-0.21 w[\% \mathrm{H}]_{s}
$$

$$
\begin{aligned}
& w[\% \mathrm{H}]_{e}=\frac{C^{\prime \prime} V_{m} \cdot \sqrt{K_{1} a_{O^{2-}}} \cdot k_{1}\left(k_{3} \cdot \rho_{s} \cdot V_{m}-17 C^{\prime} A \cdot \beta \cdot \rho_{m}\right)}{17 A^{2} \cdot \beta^{2} \cdot \rho_{m}-C^{\prime} A \cdot \beta \cdot k_{m} \cdot \rho_{s} \cdot V_{m}-17 A^{2} \cdot \beta^{2} \cdot k_{S}^{2} \cdot \rho_{m}+A \cdot \beta \cdot k_{1} \cdot k_{3} \cdot \rho_{s} \cdot V_{m} \sqrt{\frac{\pi t_{e}}{D}} \cdot \sqrt{p_{H_{2} O}} / p^{\Theta}} \\
& +\frac{C^{\prime \prime} V_{m} \cdot k_{1} \cdot k_{3} \cdot \rho_{s} \cdot \beta}{17 A^{2} \cdot \beta^{2} \cdot \rho_{m}-C^{\prime} A \cdot \beta \cdot k_{m} \cdot \rho_{S} \cdot V_{m}-17 C^{\prime \prime} A^{2} \cdot \beta^{2} \cdot k_{S}^{2} \cdot \rho_{m}+A \cdot \beta \cdot k_{1} \cdot k_{3} \cdot \rho_{s} \cdot V_{m} \sqrt{\frac{\pi t_{e}}{D}} \cdot w[\% \mathrm{H}]_{s}} \\
& +\frac{C^{\prime \prime} V_{m} \cdot k_{3} \cdot\left(C^{\prime \prime} k_{1} \cdot \rho_{m} \cdot V_{m}-17 C^{\prime} A \cdot \beta \cdot \rho_{s}\right)}{\rho^{\pi t_{e}}}
\end{aligned}
$$$$
17 A^{2} \cdot \beta^{2} \cdot \rho_{m}-A \cdot \beta \cdot k_{m} \cdot \rho_{s} \cdot V_{m}-17 C^{\prime} A^{2} \cdot \beta^{2} \cdot k_{S}^{2} \cdot \rho_{m}+A \cdot \beta \cdot k_{1} \cdot k_{3} \cdot \rho_{S} \cdot V_{m} \sqrt{\frac{\pi t_{e}}{D}}
$$ 
Based on the experimental data and substitution of Eq. (19), 6 equations can be obtained. Combination of two of the 6 equations, 20 groups of the value of $A_{1}, A_{2}$ and $A_{3}$ can be calculated. By substitution of these values, 20 formulas of the relational expression of $w[\% \mathrm{H}]_{\mathrm{e}}, w[\% \mathrm{H}]_{\mathrm{s}}$ and $p_{\mathrm{H}_{2} \mathrm{O}}$ can be expressed. The relational expression of $w[\% \mathrm{H}]_{\mathrm{e}}, w[\% \mathrm{H}]_{\mathrm{s}}$ and $p_{\mathrm{H}_{2} \mathrm{O}}$ in the process of electroslag remelting under the experimental condition of hydrogen is given as follows:

$$
w[\% \mathrm{H}]_{e}=0.359 w[\% \mathrm{H}]_{S}+0.016 \sqrt{p_{\mathrm{H}_{2} \mathrm{O}} / p^{\Theta}}+0.525
$$

The formula can be used to forecast the final hydrogen content in ingot after the electroslag remelting process from the initial hydrogen content in ingot and the moisture before the remelting.

\section{Conclusions}

(1) The atmosphere has a great effect on the hydrogen content in steel during ESR process. When the argon saturated with water vapor at $10^{\circ} \mathrm{C}$, the variation of hydrogen content in ingot is not obvious during the constant temperature process, and the original hydrogen content in steel is $2.4 \mathrm{ppm}$, after 2 hours the hydrogen content increases to $2.7 \mathrm{ppm}$. When the argon saturated with water vapor at $30^{\circ} \mathrm{C}$, the water in the atmosphere diffuses into steel rapidly, $2 \mathrm{~h}$ later the hydrogen content in the steel reaches the maximum and maintain a constant.

(2) During ESR process, the hydrogen content in steel increases firstly to maximum and later decreases to the minimum. The final equilibrium hydrogen content in steel depends on the initial hydrogen content in steel.

(3) Combined with the experiment data under different argon protection, a formula is proposed to describe the relationship between $w[\% \mathrm{H}]_{\mathrm{e}}, w[\% \mathrm{H}]_{\mathrm{s}}$ and $p_{\mathrm{H}_{2} \mathrm{O}}$ in the process of electroslag remelting under the experimental condition of hydrogen as follows:

$$
w[\% \mathrm{H}]_{e}=0.359 w[\% \mathrm{H}]_{S}+0.016 \sqrt{p_{H_{2} O} / p^{\Theta}}+0.525
$$

\section{Acknowledgement}

This work was supported by the fund of Liaoning Shihua University (2017XJJ-008) and National Natural Science of China (51704151).

\section{References}

1. Shi CB, Chen XC, Guo HJ, Zhu ZJ, Ren H. Assessment of oxygen control and its effect on inclusion characteristics during electroslag remelting of die Steel. Steel Research International. 2012;83(5):472-486.
2. Mattar TMT, Fathy AM, El-Faramawy HSR, Eissa MM, ElFawakhry KAR. Optimization of Desulphurization of tool steels during EAF and ESR Processes. In: Metal 2001; 2001 May 15-17; Ostrava, Czech Republic.

3. Masui A, Sasajima Y, Sakata N, Yamamura M. Some Important Factors Affecting Hydrogen Pick-up and Oxidation During ESR Treatment. Tetsu-to-Hagane. 1977;63(13):2181-2190.

4. Banya S, Hino M, Nagasaka T. Thermodynamics of $\mathrm{CaO} 2$ based slag for refining of high purity steels. In: Proceedings of the First International Conference on Ultra High Purity Base Metals (UHPM-94); 1994 May 24-27; Kitakyushu, Japan.

5. Maity SK, Ballal NB, Goldhahn G, Kawalla R. Development of Ultrahigh Strength Low Alloy Steel through Electroslag Refining Process. ISIJ International. 2009;49(6):902-910.

6. Takagi S, Toji Y, Hasegawa K, Tanaka Y, Roessler N, Hammer B, Heller T. Hydrogen Embrittlement Evaluation Methods for Ultra-high Strength Steel Sheets for Automobiles. International Journal of Automotive Engineering. 2010;1(2):7-13.

7. Ohaeri E, Eduok U, Szpunar J. Hydrogen related degradation in pipeline steel: A review. International Journal of Hydrogen Energy. 2018; 43(31): 14584-14617

8. Brandenberg J, Sichen D. Water vapor solubility in ladlerefining slags. Metallurgical and Materials Transactions $B$. 2006;37(3):389-393.

9. Li ZB, ed. Electroslag Metallurgy Theory and Practice. Beijing Metallurgical Industry Press; 2010.

10. Brandenberg J, Yu L, Sichen D. Water capacity model of Al2O3-CaO-MgO-SiO2 quaternary slag system. Steel Research International. 2007;78(6):460-464.

11. Kato M, Hasegawa K, Nomura S, Inouye M. Transfer of Oxygen and Sulfur During Direct Current Electroslag Remelting. Transactions of the Iron and Steel Institute of Japan. 1983;23(7):618-627.

12. Nagasaka T, Hino M, Ban-Ya S. Interfacial kinetics of hydrogen with liquid slag containing iron oxide. Metallurgical and Materials Transaction B. 2000;31(5):945-955.

13. Romanov ON, Novokhatskii IA, Kozhukhar VY, Belof BF, Bereihko BI, Mazur YY. Hydrogen permeability of standard electroslag remelting fluxes. Steel in the USSR. 1989;19(7):295-297.

14. Dong YW, Jiang ZH, Liang LK, Li ZB. Hydrogen permeability of slags containing calcium fluoride. Journal of Central South University of Technology. 2011;18(4):1063-1067.

15. Nafziger RH, ed. The Electroslag Melting Process. Albany: Albany Metallurgy Research Center; 1976.

16. Mitchell A. The Chemistry of ESR Slags. Canadian Metallurgical Quarterly. 1981;20(1):101-112.

17. Chuiko NM, Borodulin VG, Moshkevich EI, Koval AE. The behavior of hydrogen in electroslag remelting. Metallurgist. 1977;21(7):454-456.

18. Nakamura Y, Harashima K. Hydrogen contents of slag and ingot in the ESR process. Tetsu-to-Hagane. 1977;63(8):1235-1243.

19. Niimi T, Miura M, Matumoto S. An evaluation of the ESR large ingot. In: Proceedings of the 4th International Symposium on Electroslag Melting Process; 1973; Tokyo, Japan. p. 322-336. 
20. Jiang ZH, Dong YW, Liang LK, Li ZB. Hydrogen Pick-Up During Electroslag Remelting Process. Journal of Iron and Steel Research, International. 2011;18(4):19-23.
21. Dong YW, Jiang ZH, Liang LK, Li ZB. Behavior of Hydrogen during Electroslag Remelting Process. Materials Science Forum. 2011;675-677:843-846. 